\title{
Molecular Architecture and Morphology Homogenization of Polycarbonate-Crosslinked Epoxy Resins
}

\author{
Eamor M. Woo ${ }^{\dagger}$ and Chean Cheng Su \\ Department of Chemical Engineering, National Cheng Kung University, \\ Tainan, Taiwan 701-01
}

(Received November 11, 1996)

\begin{abstract}
This study demonstrates the formation of a network structure by crosslinking of an epoxy with bisphenol-A polycarbonate (PC) by via hydroxyl and carbonate groups upon heating without any amine or anhydride curing agents. The changes of morphology of the crosslinked network structure during reactions was examined. The observation of intermediate morphology prior to the final network suggests that exchange reactions yield various product species in localized regions that introduced some temporary non-homogeneity; nevertheless, the final stage of reactions led to a homogenized epoxy/PC network. A likely molecular architecture of network building is discussed.

KEY WORDS Epoxy / Polycarbonate / Transreaction / Exchange Reaction / Network
\end{abstract}

Epoxy resins are usually formulated with various thermoplastic polymers, rubbers, or other thermosetting resins. Studies have shown that mixtures of tetraglycidyl diaminodiphenyl sulfone (TGDDM)/bisphenol-A polycarbonate (PC) mixtures of various compositions cured with an aromatic amine (4,4'-diamino diphenyl sulfone, DDS) lead to a crosslinked network with rare homogeneity. ${ }^{1}$ A continuing FT-IR study ${ }^{2}$ demonstrates that by excluding DDS and using only TGDDM and PC as a simplified model, chemical transreactions take place between the carbonyl in PC and the epoxide group in TGDDM acting as a tertiary amine auto-catalyst. The unheated TGDDM/PC liquid mixtures contain all $\phi-\mathrm{O}-\mathrm{CO}-\mathrm{O}-\phi$ linkages characteristic of the original unreacted PC chains; nevertheless, the structure of the transreacted solids contains $\phi$-carbonate- $\phi$ and/or $C$-carbonate-C linkages, where symbols " $\phi$ " and " $C$ " adjacent to the carbonate group indicate the phenyl or aliphatic chain, respectively. This suggests that transreactions result in breaking the PC chains and grafting the fragmented PC segments onto the homo-polymerizing TGDDM oligomers. It is these reactions that lead to a branched or ultimately a crosslinked TGDDM-PC network.

Similar chemical reactions have also been demonstrated between PC and a difunctional epoxy resin (diglycidyl ether of bisphenol-A, DGEBA). ${ }^{3-5}$ Related studies show that the chemical links between the epoxide (or hydroxyl) and carbonate groups help ensure that the PC component is not segregated into separate phase domains as the epoxy and hardener components undergo cross-linking reactions to form a network structure. Phenoxy can be viewed as a homo-polymerized epoxy chain whose repeat unit resembles that of DGEBA. Thus, structurally, phenoxy and DGEBA are similar. A transreacted $\mathrm{PC} /$ phenoxy blend system undergoes exchanges reaction between the hydroxyl group of phenoxy and the carbonate groups of the PC. Additionally, a heated and exchanged $\mathrm{PC} /$ phenoxy polymer blend exhibits a single $T_{\mathrm{g}}$, but actually possesses a multi-phase morphology. ${ }^{6}$
Ohsako et al. $^{7}$ reported the morphology and mechanical properties of an elastomer-modified epoxy (EMDGEBA)/PC system and concluded that the introduction of PC induced a micro-dispersed structure and improved the elongation of the epoxy resin. How ever, it must be noted that their epoxy/PC system contained some carboxyl-terminated butadiene acrylonitrile (CTBN). Thus, the phase behavior is obscured by the presence of the rubber. To investigate the true phase morphology of epoxy/PC systems and effects of PC on the properties, it is critical to realize that components other than epoxy and PC must be excluded. In 1992, Hourston et $a l^{8}$ have reported that PC addition into DGEBA cured with diethylenetriamine (DETA) results in miscibility and slight increase in $K_{\mathrm{IC}}$. At that time, they were not aware of extensive exchange reactions taking place between PC and epoxy; thus, the term miscibility was actually not proper to describe the homogeneity of the amine-cured epoxy/PC network. More recently, exchange reactions leading to cleavage of the PC polymer chains have been demonstrated between DGEBA epoxy and $\mathrm{PC}^{3,4}$ as well as between TGDDM and PC. ${ }^{1,2}$ Separate investigation has also been conducted by Bucknall et al. ${ }^{9}$ who suggest that addition of PC in the DGEBA epoxy (cured with methylene dianiline) may lead to molecular fragmentation upon heating to $150^{\circ} \mathrm{C}$ as they found that the fracture toughness of the modified epoxy system was not improved by the addition of PC. Don and Bell ${ }^{10}$ published a paper in agreement with our earlier findings ${ }^{1-4}$ by claiming that PC chain is fragmented at the carbonate linkages and trans-esterification (with alcoholysis and alcohol exchange) occurs between the secondary (dangling) hydroxyl groups in the epoxy resin and the carbonate groups in PC. Chang et al. ${ }^{11}$ on the other hand, claim that a tertiary amine has to be present in the system to cause a chain exchange reaction. However, their view essentially contradicts with the many recently reported factual cases where exchange reactions have been demonstrated in various epoxy/PC systems that do not necessarily contain tertiary amine species. ${ }^{3-5,9,10}$

\footnotetext{
${ }^{\dagger}$ Author to whom correspondence should be addressed (Fax: $\left.+886-6-234-4496\right)$.
} 
The aim of this study was to investigate further network building in epoxy/PC systems. Evolution of morphology during reaction was dynamically monitored. For separate analysis and identification of the constituents, partially solidified epoxy/PC samples at intermediate heating times were separated into dissoluble and indissoluble portions by solvent extraction. Finally, possible network structure is proposed by illustrating three possible model schemes.

\section{EXPERIMENTAL}

\section{Materials and Preparation}

Two epoxy resins were used in this study. One was a difunctional epoxy, diglycidyl ether of bisphenol-A (DGEBA) (Epikote-828, Shell Corp.), with an epoxide equivalent weight of $187 \mathrm{~g}$, and the other was a tetrafunctional epoxy, tetraglycidyl-4,4'-diamino-diphenylmethane (TGDDM) (Ciba-Geigy MY-720). BisphenolA polycarbonate (PC) was GE Lexan ${ }^{\mathrm{R}} \mathrm{H}-1130$, which has $M_{w}=23000 \mathrm{~g} / \mathrm{mol}^{-1}$. Solution blending was done for preparation of epoxy/PC samples. First, the epoxy (TGDDM or DGEBA) and PC were co-dissolved and solution-blended to form a homogeneous mixture with the aid of a common solvent (dichloromethane). Care was taken to avoid PC solvent-induced crystallization, which means that usually maintaining at a temperature slightly above room temperature is necessary during casting and degassing. The residual solvent in the blended mixture was driven off in a circulation oven with an exhaust fan at room temperature, followed by removal in a vacuum oven at $40^{\circ} \mathrm{C}$ for $48 \mathrm{~h}$ or longer. A transparent film was obtained at the end of this step.

For every hundred parts epoxy, the epoxy/PC mixtures were prepared with the PC component constituting 20, 100 , and 300 parts per hundred parts (phr), respectively, with respect to the epoxy constituent. The composition ratios in epoxy/PC system thus corresponded to $5: 1$, $1: 1$, and $1: 3$, respectively. For investigation of the effects of $\mathrm{PC}$ at relatively low contents, additional mixtures of epoxy/PC samples were prepared in two ratios: 20:1 and $10: 1$, where the PC content in the mixtures corresponded to 5 and $10 \mathrm{phr}$, respectively. The epoxy/PC mixtures of various compositions were then heated at an isothermal temperature of $177^{\circ} \mathrm{C}$ (a typical cure temperature for most high-performance epoxies) for various time. The reacted samples were extracted with dichloromethane and broken into two portions: the residual solid and extracted solution, both separately kept for various analysis. Results of the extracted solutes and residual solids were compared with the results of the parent heated PC/epoxy samples.

\section{Apparatus}

Fourier transform infrared spectra (FT-IR, Nicolet Magna-550) were obtained at $4 \mathrm{~cm}^{-1}$ resolution and averages were obtained from a number of at least 64 scans in the standard wavenumber range of $400-4000$ $\mathrm{cm}^{-1}$. IR was performed to identify changes of the functional groups in the molecular chains of the networking products. IR measurements were carried out on thin films cast onto potassium bromide $(\mathrm{KBr})$ disk or by a powder mixing technique. The soluble portion (extracted solute) and the parent epoxy/PC samples were analyzed in thin films cast on $\mathrm{KBr}$, while the leached solid samples (indissoluble portion) were ground and mixed with $\mathrm{KBr}$ powder and pressed into discs.

Scanning electron microscopy (SEM, JEOL JXA-840) characterization was performed to examine the morphology of the heated epoxy/PC samples of different reaction extents, which were all freeze-fractured and subsequently coated with gold vapor deposition using a vacuum sputterer. Solvent etching of samples was performed whenever necessary.

\section{RESULTS AND DISCUSSION}

\section{Formation of Network}

Network-forming in the TGDDM/PC mixtures subjected to heating was first noted by the persistent presence of indissoluble residues upon dissolution of the heated solid in dichloromethane. The weight percentages of the leached solid with respect to the parent TGDDM/ PC samples reflect the extent of transreactions leading to a crosslinked network. The mixtures after short times of reactions (at $177^{\circ} \mathrm{C}$ or higher) were almost completely soluble in the solvent. After certain times ( 50 min or longer), the heated epoxy/PC sample gradually became partially indissoluble. Eventually, after extended heating time at $177^{\circ} \mathrm{C}$, the samples became totally indissoluble. The dynamic changes leading eventually to a crosslinked network of the epoxy/PC mixtures were investigated and reported.

Figure 1 shows comparative plots of weight percentages of the leached solid (indissoluble) in the parent samples as a function of heating time at $177^{\circ} \mathrm{C}$ for the three epoxy/PC mixtures of compositions: $5 / 1,1 / 1$, and $1 / 3$, respectively. The results of comparison shows that at times shorter than $50-60 \mathrm{~min}$, all three samples were almost completely soluble in the solvent, indicating that the extent of reaction and/or crosslinking were rather small. For heating times shorter than $50-60 \mathrm{~min}$, the heated samples of all three compositions, being not crosslinked enough, were almost completely soluble in dichloromethane with no or very little solid residue. The steep rise of the curves beginning at the heating time of $60 \mathrm{~min}$ suggests that the TGDDM/PC system approaches the gel point at this time. Here, the onset point of sudden increase in the residual solid $\mathrm{wt} \%$

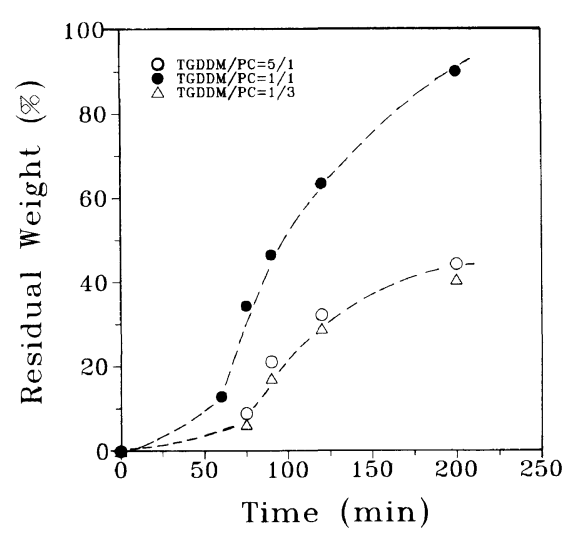

Figure 1. Plots of residual weight percent of leached solid portion with respect to the parent TGDDM/PC heated at $177^{\circ} \mathrm{C}$ for various times. Compositions: $(\bigcirc) 5 / 1 ;(\bullet) 1 / 1 ;(\triangle) 1 / 3$. 
indicates the formation of a gelled state. At times greater than $60 \mathrm{~min}$, the weight percentages of the indissoluble solids with respect to the parent samples are seen to increase steadily with heating time for each composition. Of the three compositions, the $1 / 1$ composition yielded the highest average percentage of indissoluble crosslinked solid, indicating that this composition possesses the greatest cross linking density or highest extent of transreaction and/or alcoholysis grafting. An earlier study on probing the mechanism of exchange reactions has pointed out that when PC is present in great excess to epoxy, the chain exchange reactions may be limited to a lesser extent when PC as the epoxy (TGDDM) becomes the limiting species. ${ }^{2}$

The physical differences between the extracted solute and leached solid samples have been previously studied using DSC to determine the $T_{\mathrm{g}}{ }^{12}$ Both the $T_{\mathrm{g}}$ 's of the leached solid portion and the corresponding parent epoxy/PC sample have been found to increase with heating time at $177^{\circ} \mathrm{C}$. By contrast, the $T_{\mathrm{g}}$ 's of the extracted solute samples remain constantly much lower (than the parent sample or the leached solid) at about $-3^{\circ} \mathrm{C}$ and do not seem to change with heating time. The lower $T_{\mathrm{g}}$ can be explained by the fact that the extracted solute consists primarily of a mixture of fragmented PC chains of low $M_{w}$, epoxy/PC oligomers with a terminal cyclic carbonate group, and probably some unreacted epoxy monomer as well. The compositions of mixtures have been found to influence $T_{\mathrm{g}}$ of the network after reactions. The average $T_{\mathrm{g}}$ 's of the leached solid portion and parent epoxy/PC samples are higher for this composition $(1 / 1)$ where the carbonate groups of PC and epoxide groups of TGDDM are near the stoichiometric equivalency than the other compositions with either high contents of PC or TGDDM. This can be easily attributed to the fact that the cross linking density in the heated epoxy/PC network of $1 / 1$ composition is higher than that of $5 / 1$ composition or $1 / 3$ composition. This is easily understandable since in the absence of a regular amine or anhydride hardener, the role of the PC component can be viewed as a cross linking agent.

\section{Morphology Changes of Epoxy/PC Network}

Morphological studies were conducted on examining the dynamic changes of morphology structure of the heated TGDDM/PC mixtures. The epoxy/PC samples at various heating intervals were withdrawn, fractured, and slightly etched with dichloromethane for examination using SEM.

Figures 2a, b show scanning electron micro graphs of the TGDDM/PC (Composition: 1/1) samples heated at $177^{\circ} \mathrm{C}$ for (a) 60 and (b) 90 , respectively. Figure 2a shows the micro graph of the heated epoxy/PC sample (heated for $60 \mathrm{~min}$ ) after solvent etching. Apparently, at $60 \mathrm{~min}$ of heating, the sample was just about to reach an initial gel point. Therefore, a good portion of the sample could still be etched out with the $\mathrm{CH}_{2} \mathrm{Cl}_{2}$ solvent, leaving the remaining gelled/crosslinked solid to appear like a 3-D mesh-like braided skeleton. Note that the hollow craters are the spots from which the low $-M_{w}$ species or lessreacted product species were extracted. Figure $2 b$ is a micrograph of the epoxy/PC sample heated for $90 \mathrm{~min}$. The graph shows that less species could be extracted from
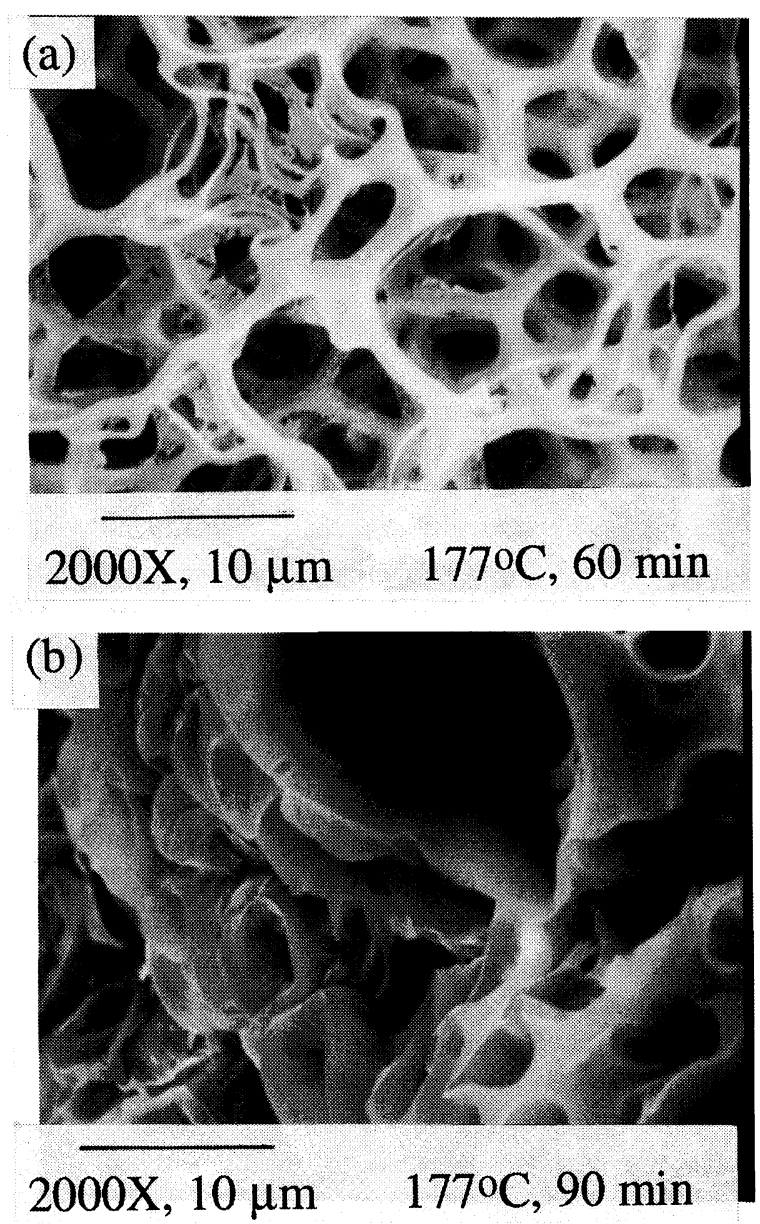

Figure 2. SEM micrographs of TGDDM/PC (1/1) samples cured at $177^{\circ} \mathrm{C}$ for (a) 60 , and (b) $90 \mathrm{~min}$. Sample preparation involved etching with $\mathrm{CH}_{2} \mathrm{Cl}_{2}$ solvent.

the epoxy/PC heated for this longer time. Therefore, upon solvent etching, the $90 \mathrm{~min}$-heated epoxy/PC sample exhibited a slightly more developed network with still some etched-out craters.

Note that the intermediate morphology (for mixtures heated for shorter times) before reaching a finally crosslinked structure was complex and more difficult to interpret. SEM examination revealed that the network structure displayed a 3-D honeycomb-like interconnected skeletons for the heated samples at intermediate stages of reactions just reaching beyond the gel point. This morphology might have also been complicated partially due to solvent-induced changes (swelling, extraction, and re-deposition, etc.) upon solvent etching of the samples. This complication is limited, and the intermediate morphology as revealed by the dynamic observation can still be regarded as closely reflecting the network partially formed just over the gel point. The intermediate morphology indicates that before the final homogeneous network is reached, the exchange reactions can randomly produce various low $-M_{w}$ species that aggregate in localized spots. The intermediate morphology may not be quite homogeneous. Eventually, with continuing reactions leading to crosslinking, grafting, and/or copolymerization between the species, the final network is homogenized.

Figures $3 \mathrm{a}$ and $3 \mathrm{~b}$ show the micrographs of the 
TGDDM epoxy/PC samples heated for (a) 200, and (b) $120 \mathrm{~min}$, respectively. Especially, the fractured surface of the $200 \mathrm{~min}$-cured sample (after solvent etching) exhibits a characteristic pattern of bland fracture-induced
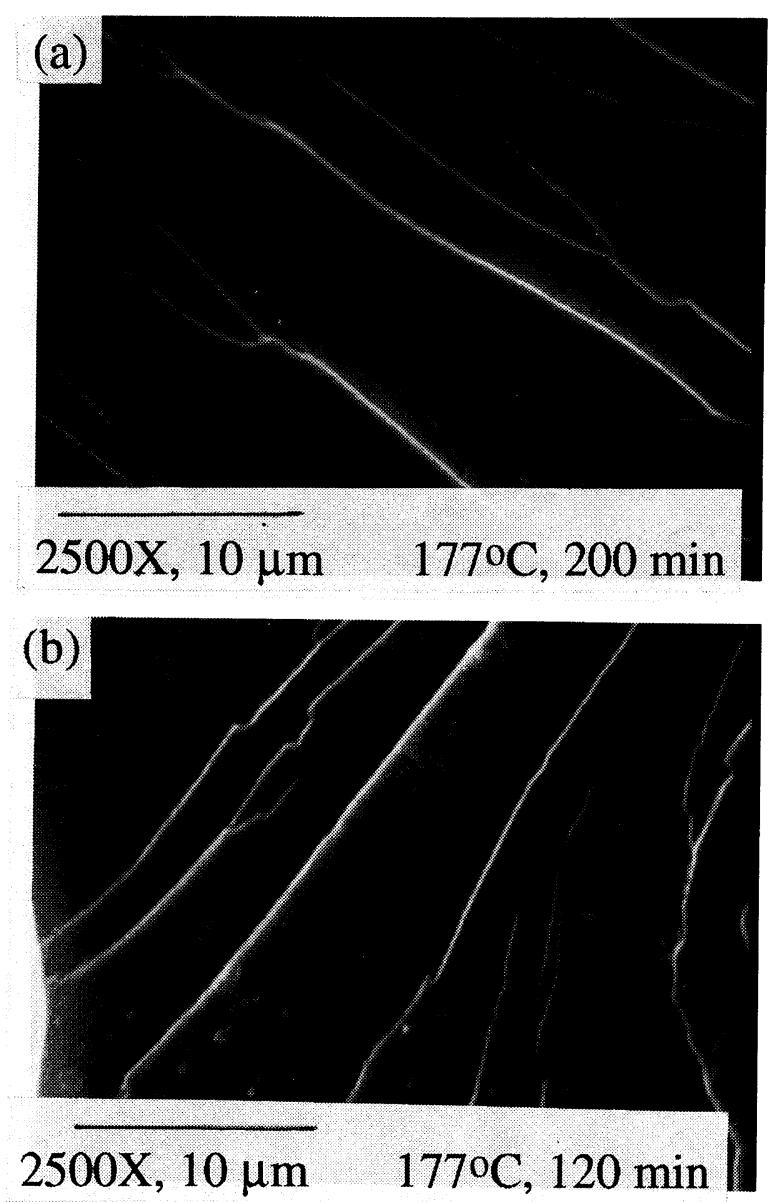

Figure 3. Scanning electron micrographs of TGDDM/PC (1/1) samples cured at $177^{\circ} \mathrm{C}$ for longer time of (a) 200 , and (b) $120 \mathrm{~min}$. Sample preparation involved similar etching with $\mathrm{CH}_{2} \mathrm{Cl}_{2}$. strain propagation, suggesting that virtually little was etched out from the crosslinked network. The smooth topology reflects a crosslinked, brittle, network not much affected or swollen by the solvent. To a less extent, the 120 min-cured sample, with some crosslinking, also remains comparatively intact in the solvent, and solvent etching is not easily recognizable in the SEM graph. Earlier, Figure 1 pointed out that the state of crosslinking for the $120 \mathrm{~min}$-cure sample was still less in comparison to the $200 \mathrm{~min}$-cured one. The results of fracture morphology suggest that a crosslinked network increasingly unaffected by the solvent was found in the TGDDM/PC samples subjected to heating times longer than $120 \mathrm{~min}$. Samples of other epoxy/PC compositions $(5 / 1$ and $1 / 3)$ were found to be semi-soluble due to insufficient crosslinking densities even after long heating times. They were thus not studied using SEM as these samples did not stay intact enough for microscopy sample preparation.

\section{Molecular Architecture in Network Structure}

Figure 4 shows the full spectra for the (I) extracted solutes, (II) leached solid, and (III) the parent heated TGDDM/PC (1/1) sample $\left(177^{\circ} \mathrm{C}\right.$-heated for $\left.200 \mathrm{~min}\right)$. Note that the hydroxyl absorption peak is the smallest for the solute sample (Curve-I), indicating very little reaction for the extracted solutes. By comparison, the hydroxyl peak is very pronounced in the leached solid (Curve-II), suggesting that the crosslinked network contains epoxy chains of homo-polymerized TGDDM molecules, which eventually are inter-connected with PC to form a network. In addition, the absorption peaks of carbonyl of aromatic vs. aliphatic linkages (at 1770$\left.1750 \mathrm{~cm}^{-1}\right)$ and terminal carbonate group $\left(1810 \mathrm{~cm}^{-1}\right)$ are drastically different. Owing to excess stoichiometry of the epoxy, the epoxide absorbance peak is observed in all three curves (from top to bottom: leached solid, parent heated sample, and extracted solute, respectively)

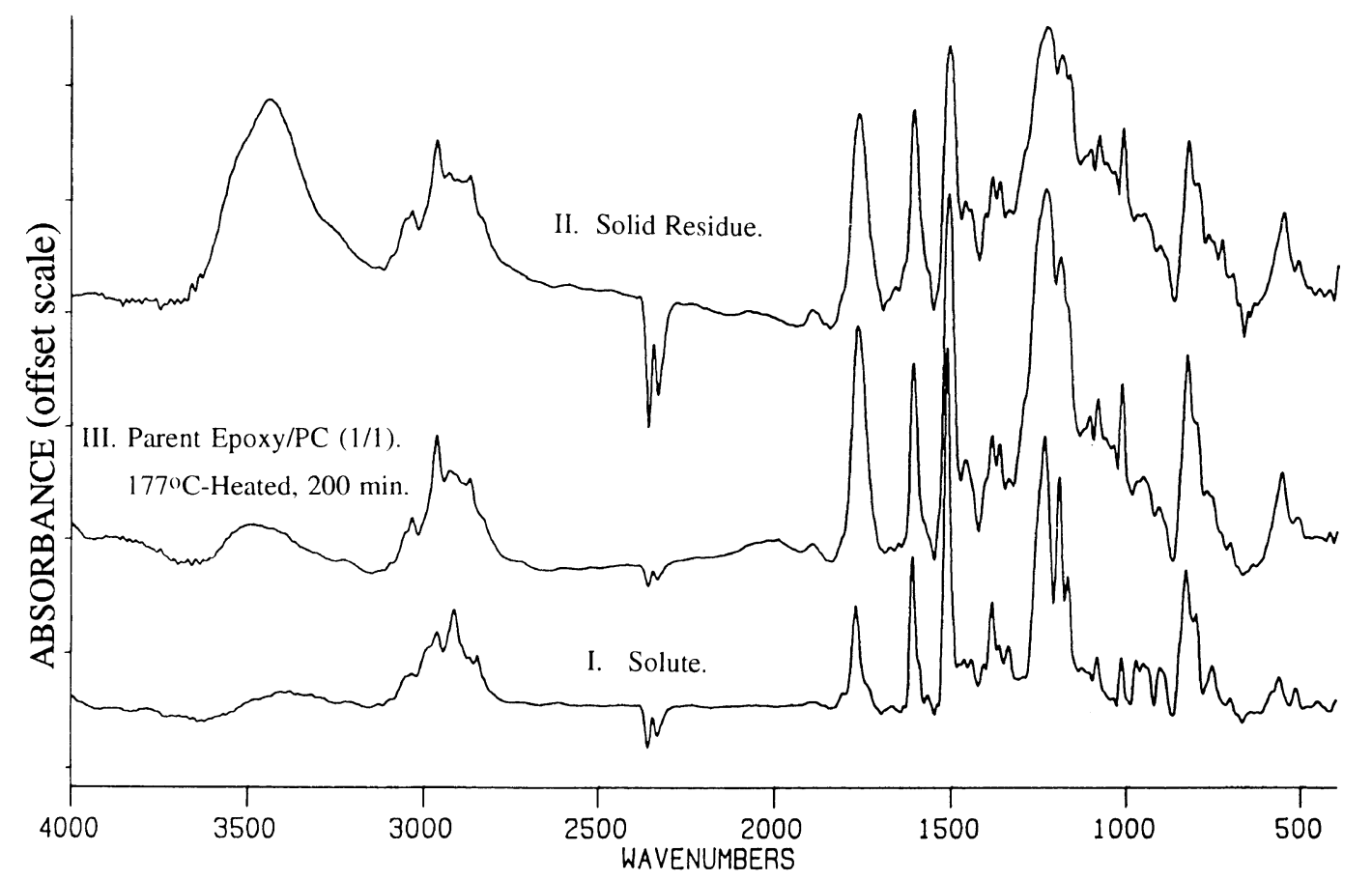

Figure 4. FTIR spectra for (I) extracted solute, (II) leached solid, from (III) parent TGDDM/PC (1/1) $\left(177^{\circ} \mathrm{C}\right.$-heated, $\left.200 \mathrm{~min}\right)$. 
(A) Extracted solute from epoxy $/ \mathrm{PC}(1 / 1)$ heated at $177^{\circ} \mathrm{C}$

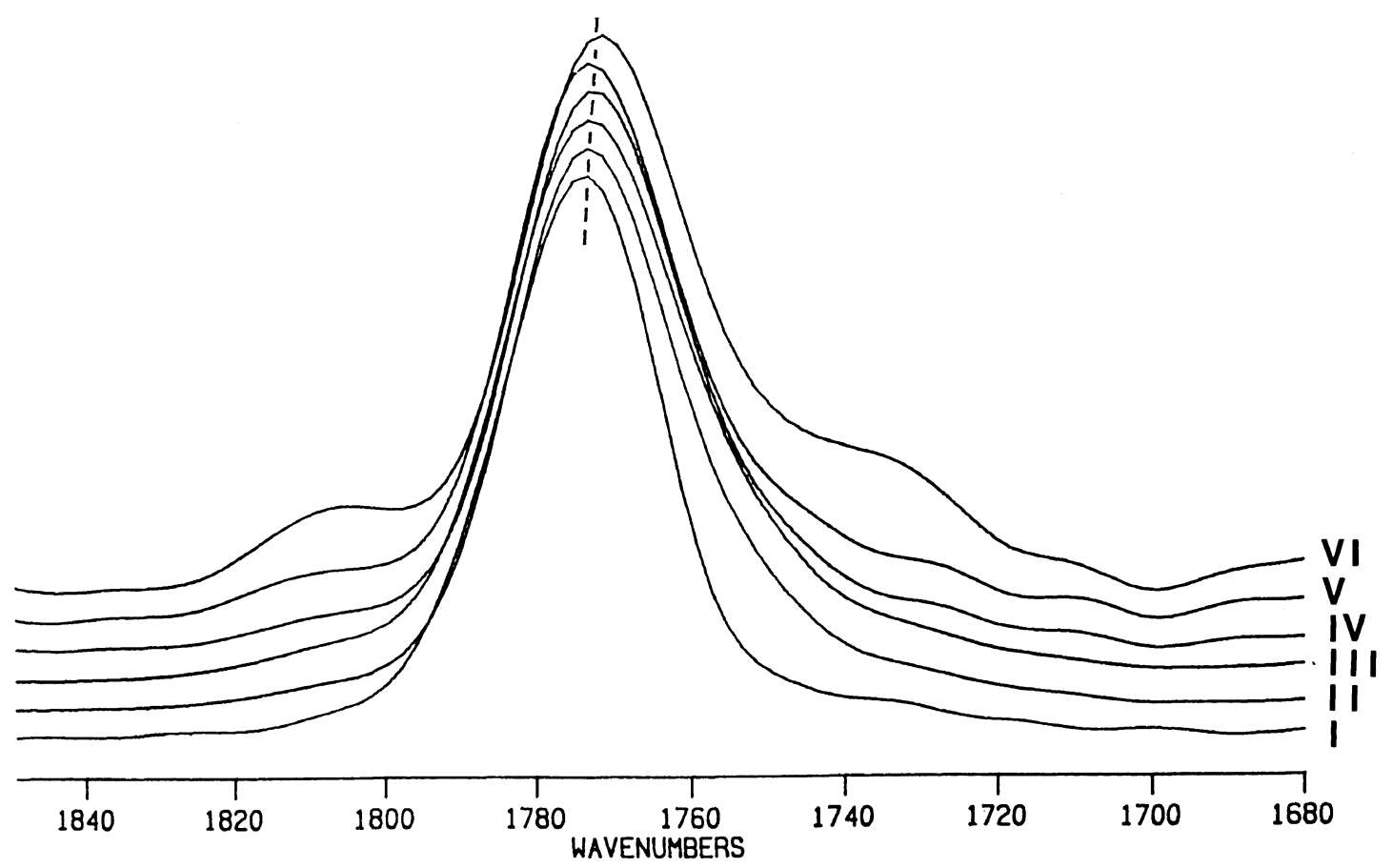

(B) Solid residue from parent epoxy/PC $(1 / 1)$ heated at $177^{\circ} \mathrm{C}$

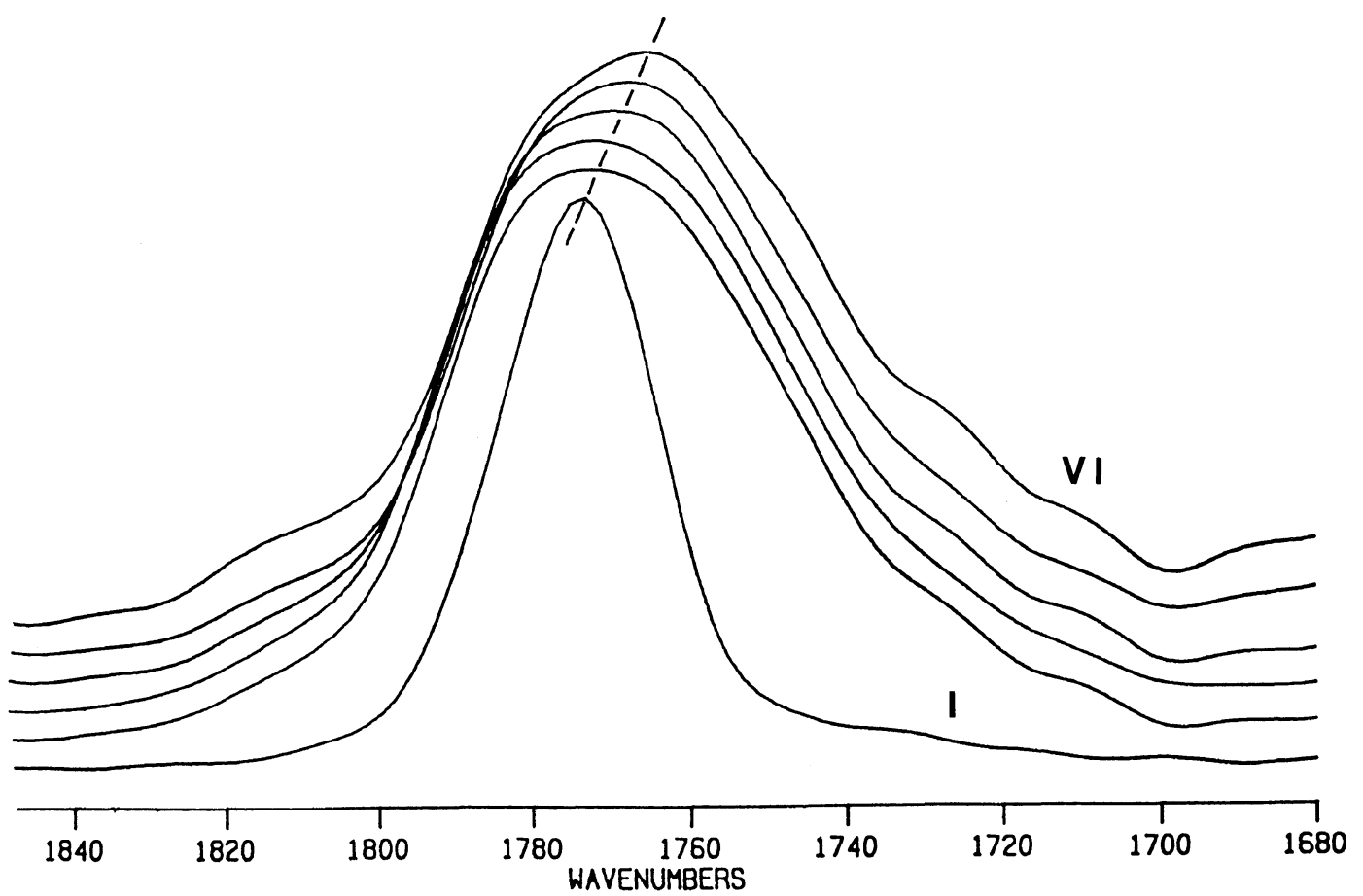

Figure 5. Carbonyl absorbance peaks for: (A) the extracted solute, and (B) the leached solid portion prepared from the parent TGDDM/PC (1/1) heated for (I) 0 , (II) 60, (III) 75, (IV) 90 , (V) 120, and (VI) 200 min, respectively.

even though the parent epoxy/PC was heated at $177^{\circ} \mathrm{C}$ for $200 \mathrm{~min}$. The extracted solute (Curve-I) exhibits a more pronounced peak intensity for the epoxide absorbance, indicating that a greater portion of the un- reacted epoxy (or partially reacted epoxy) was extracted out from the parent epoxy/PC sample. The spectrum for the extracted solute shows only a very weak absorption corresponding to the cyclic carbonate stretching 
at $1810 \mathrm{~cm}^{-1}$ as a function of increasing heating time. However, it has been demonstrated that for the epoxy/PC mixtures with excess TGDDM epoxy, the IR absorption of cyclic carbonate species becomes more pronounced. ${ }^{12}$ This is explained by the fact that at longer heating time, more side reaction leading to incomplete oligomers of terminal cyclic chains is resulted between TGDDM and PC.

Figure 5 shows the offset plots of the carbonyl IR absorbance peaks (located initially at $1770 \mathrm{~cm}^{-1}$ ) for the samples of (A) the extracted solute, and (B) the leached solid portion, each prepared from the parent TGDDM/ PC (1/1) heated for $0,60,75,90,120$, and $200 \mathrm{~min}$, respectively (from lower to upper curves). Carbonyl absorbance shifts of the carbonyl group in the extracted solute (5-A) and leached solid (5-B) are indicated with dashed lines with respect to the IR absorbance peak for the carbonate group of unheated epoxy/PC mixture at $1770 \mathrm{~cm}^{-1}$. Evidently, Figure $5 \mathrm{~A}$ shows that the carbonyl absorption peak for the extracted solute sample does not change with time of heating, indicating that the extracted solute represents the portion that did not undergo reactions and remained free. By comparison, Figure 5B shows that the carbonyl absorbance peak down-shifts for the leached solid sample steadily increases with time of heating, indicating that the indissoluble solid represents the portion in the epoxy/PC network that has undergone more extensive crosslinking reactions leading to a more developed network structure.

Consequently, the leached solid from the parent crosslinked epoxy/PC sample can be expected to have a higher transreaction and alcoholysis exchange than the extracted soluble solute, which might contain primarily product species such as linear molecules, fragmented PC, or oligomeric TGDDM-PC species with cyclic carbonate end groups or terminal PC segments. ${ }^{12}$ This is shown in IR that the carbonyl stretching absorbance of the leached solid has greater average down-shift than does the solute portion. The changes with heating time are apparent indication that the reactions lead eventually to a network resulting from exchanged chemical links between the epoxy and PC. The carbonate group in the original unreacted PC polymer chain is linked to two phenyl groups, but transreaction causes changes of linkages adjacent to the carbonate group.

Our previous studies ${ }^{2,12}$ demonstrated that transreaction and/or alcoholysis exchange (between PC carbonate and epoxy hydroxyl) lead to more aliphatic linkages with the carbonate group (i.e., $\mathrm{C}-\mathrm{O}-\mathrm{CO}-\mathrm{O}-\mathrm{C}$ ), which causes downshift of the carbonyl IR absorption peak. For some types of the epoxies (such as TGDDM) that contain minimum or no hydroxyl groups available for exchange reaction, initial heat-induced reactions may lead to the generation of $-\mathrm{OH}$ groups in the epoxy segments at high temperature according to several proposed mechanisms. $^{2,13,14}$

\section{DISCUSSION}

We earlier proposed that alcoholysis (hydroxyl) exchange occurs between the secondary - $\mathrm{OH}$ groups of the epoxy monomers (or oligomers) and the carbonate groups of the PC polymer chains in the heated TGDDM/PC. ${ }^{2}$ Usually, the secondary hydroxyl groups in epoxy pre-exist or can be generated from ring-opening homo-polymerization of epoxides at high temperatures. $^{2,13,14}$ In this fashion, the fragmented PC (i.e., PC chain scission at the carbonate $\mathrm{O}-\phi$ linkage) segments are exchanged with the hydroxyl hydrogen or the epoxide groups of epoxy. Accordingly, the presence of aliphatic carbon-linked carbonate groups is indication of branching and/or crosslinking between PC and homo-polymerizing TGDDM. More detailed results from NMR and FT-IR studies that support this proposal have been published. ${ }^{12}$ Thus, the PC segments serve as crosslinks for the epoxy molecules, eventually leading to a crosslinked network if the exchange reactions are extensive enough. Depending on the carbonate sites of chain scission of the $\mathrm{PC}$ chain, the exchange reactions can lead to products including several possible epoxy/PC linkages, as followings:

(A) No Reaction, all $\phi$-carbonate- $\phi$ Linkages. The carbonate carbonyl absorbance exhibits no peak shift at all. This indicates that no exchange reaction takes place. The PC chains are not exchanged with the epoxy hydroxyl group. All as-prepared epoxy/PC mixtures without heat treatment exhibited a carbonyl absorbance with the peak location remaining the same as that of neat PC sample.

(B) Exchange Reactions by Three Possible Schemes. Exchange reactions take place between the PC and epoxy. The carbonate absorbance peaks exhibits intermediate down shift due to changes of linkages with the carbonyl group, which changes the force constant responsible for the stretching absorbance of the group. This indicates that the epoxy is crosslinked with PC segments to various extents. The epoxy may be linked with a single carbonate group. This results in $\mathrm{C}$-carbonate- $\mathrm{C}$ linkages in the chain structure, with the carbonate absorbance exhibiting a maximum down shift due to changes of linkages on both sides of the carbonyl group.

Figure 6 illustrates three possible schemes of network building, depending on the way the PC chains are fragmented. Scheme (I) shows that both ends of the PC segments are exchanged. The exchanged chains in the epoxy/PC network are characterized with the presence of $\phi$-carbonate-C links. The PC chains can be fragmented at any probabilistic location along the chain length; thus, $n$ can be any value from 1 and up. The lower the value of $n$, the higher is the crosslink density. Scheme (II) shows that one end of the PC segment is grafted onto the epoxy chain while the other end remains free. The exchanged chains in the epoxy/PC network amply possess $\phi$-carbonate-C links just as in Scheme (I), and structurally there is no way to distinguish between the structures in Schemes (I) and (II). Schemes (I) and (II) together represent the most likely crosslink chain linkages in the epoxy/PC network. Expectedly both schemes are simultaneously present with changing ratios depending on the temperature and length of heating at that temperature. Scheme (III) illustrates a possible structure resulting from a single carbonate-group linkage. The PC chain scission occurs in such way that the carbonate group is exchanged on both sides and each of the two sides is linked directly to an epoxy by exchange with the hydroxyl groups. The main feature of this linkage 


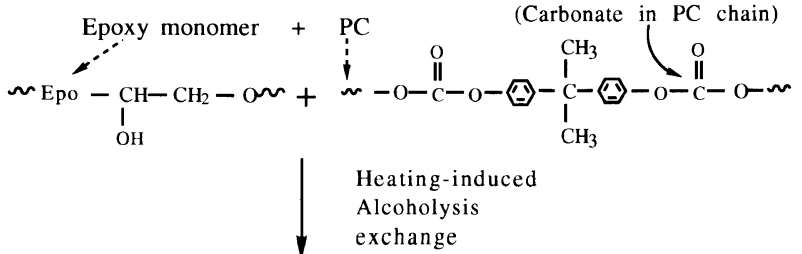

epoxy-PC network, depicted as following:
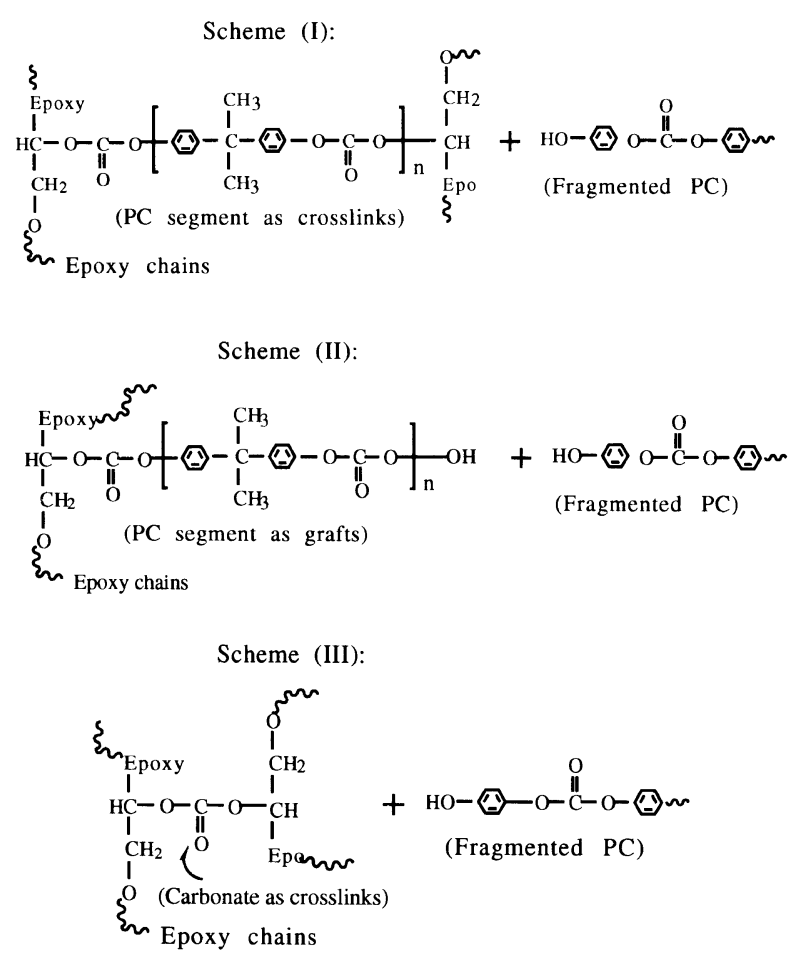

Figure 6. Three possible schemes of network building from exchange reactions between epoxy and $\mathrm{PC}$.

is formation of $\mathrm{C}$-carbonate- $\mathrm{C}$ in the chain, where the epoxy molecules are crosslinked with a single carbonate group $(\mathrm{O}-\mathrm{CO}-\mathrm{O})$, rather than with a cleaved $\mathrm{PC}$ segment as in Scheme (I). It is believed that this is a less likely but nevertheless probable chain structure.

\section{Exchange Reactions in DGEBA/PC System}

Figure 7 shows the carbonyl absorbance peaks in the FTIR spectra of the DGEBA/PC $(1 \mathrm{wt} \%)$ mixture that have been heated at the isothermal temperature of $177^{\circ} \mathrm{C}$ for various times from 0 to $200 \mathrm{~min}$. The carbonyl stretching peak apparently exhibits downshift to lower frequencies with increased heating time at $177^{\circ} \mathrm{C}$. It must be noted that the $\mathrm{PC}$ content in this sample was made extremely low ( $1 \mathrm{wt} \%$ or $1 \mathrm{phr})$ to demonstrate that the exchange reactions take place despite low PC contents.

The absorbance peak at about $1805 \mathrm{~cm}^{-1}$ is also observed in the spectrum of heated DGEBA/PC samples and its intensity seems to increase with heating time. This absorbance is attributed to the aldehyde group, a product of side isomerization of epoxy upon heating. Thus, this peak is not observed in the unheated DGEBA/PC sample. This side reaction can be suppressed if a curing agent is present in the epoxy system as it is known that this peak is not present in most normal epoxy/amine systems. In the present cases of epoxy/PC mixtures with no curing agent, PC can react with the epoxy upon heating and

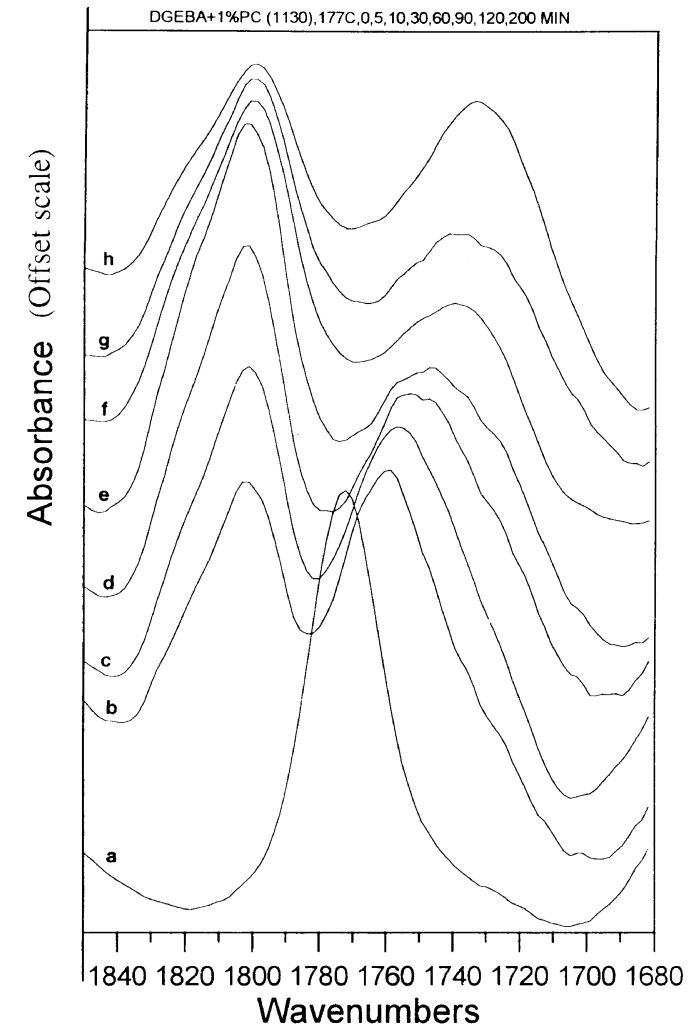

Figure 7. IR carbonyl absorbance peaks the DGEBA/PC $(1 \mathrm{wt} \%)$. The samples have been heated at $177^{\circ} \mathrm{C}$ for various times: (a) 0 , (b) 5 , (c) 10, (d) 30, (e) 60, (f) 90, (g) 120, (h) $200 \mathrm{~min}$.

act as a curing agent. In epoxy/PC mixtures with greater $\mathrm{PC}$ content, it can be shown that the side isomerization reaction leading to generation of the aldehyde peak at $1805 \mathrm{~cm}^{-1}$ is also gradually suppressed.

Figure 8 (Diagrams I \& II) shows the IR carbonyl absorption peaks for two additional DGEBA/PC mixtures containing (I) $10 \mathrm{phr} \mathrm{PC}$, and (II) $20 \mathrm{phr} \mathrm{PC}$, previously heated at $177^{\circ} \mathrm{C}$ for various times from 0 to $200 \mathrm{~min}$. Again for these two epoxy/PC samples of slightly higher PC contents, the carbonyl peak apparently down-shifts to lower wavenumbers with increased heating time at $177^{\circ} \mathrm{C}$. Note that the higher PC contents in these two samples significantly suppress the side isomerization reaction responsible for generation of the aldehyde peak at $1805 \mathrm{~cm}^{-1}$.

Figure 9 shows a plot of the carbonyl absorption peak (in $\mathrm{cm}^{-1}$ ) as a function of heating time at $177^{\circ} \mathrm{C}$ for three DGEBA/PC mixtures containing: $1 \mathrm{phr}, 10 \mathrm{phr}$, and $20 \mathrm{phr}$ of PC, respectively. As shown in Figure 7, exchange reactions occur even with only just $1 \mathrm{wt} \% \mathrm{PC}$ present in the mixture, causing a carbonyl shift roughly comparable with the other epoxy/PC mixtures with higher PC. Direct comparison shown in this plot further demonstrates that the carbonyl shift actually is slightly greater for the DGEBA/PC mixtures with less PC. In an epoxy/PC mixture with less available PC, PC chains may be cleaved into shorter segments, leading to a greater likelihood of network formation illustrated by Scheme (III). As discussed earlier, the network according to Scheme (III) has more $\mathrm{C}$-carbonate-C linkages in the chain. Consequently, the carbonyl absorbance exhibits maximum down shift due to changes of linkages on both sides of the carbonyl group. 

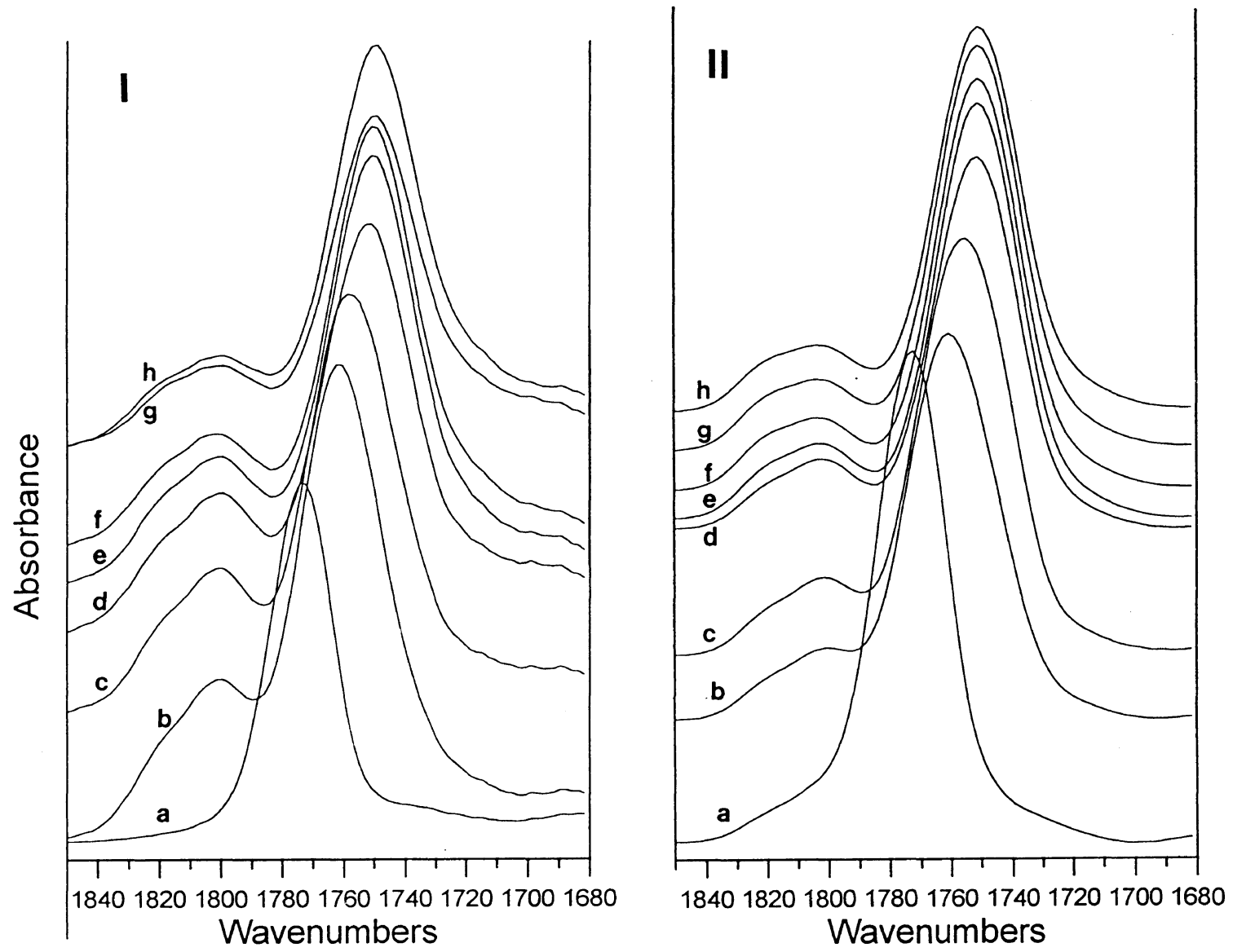

Figure 8. IR carbonyl absorbance peaks for the DGEBA/PC mixtures containing: (I) $10 \mathrm{phr}$, (II) $20 \mathrm{phr}$ of PC, previously heated at $177^{\circ} \mathrm{C}$ for (a) 0, (b) 5, (c) 10, (d) 30, (e) 60, (f) 90, (g) 120, (h) $200 \mathrm{~min}$.

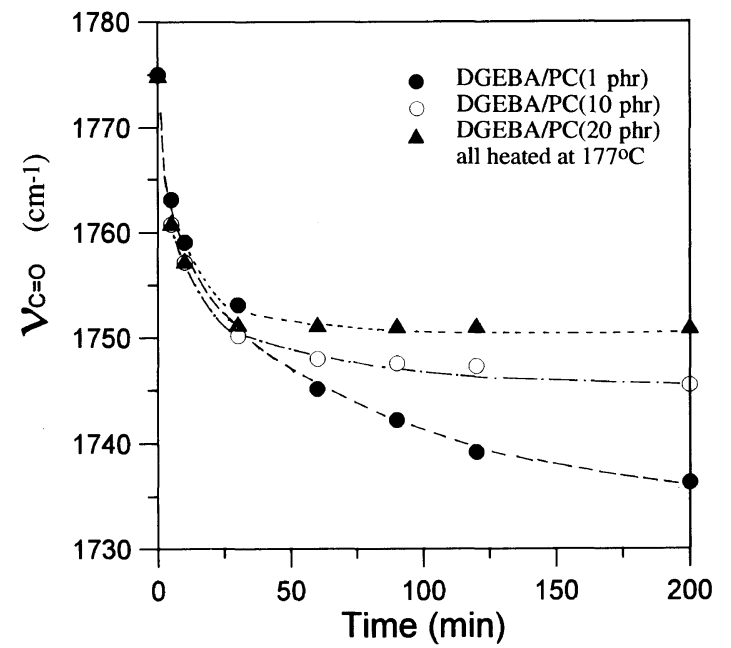

Figure 9. Plot of carbonyl absorption peak as a function of heating time at $177^{\circ} \mathrm{C}$ for three DGEBA/PC mixtures containing: (O) 1 phr, (O) $10 \mathrm{phr}$, and $(\triangle) 20 \mathrm{phr}$ of PC.

\section{CONCLUSION}

The crosslinking of epoxy with PC upon heating and resulting network structure has been proven and discussed. The indissoluble nature of the epoxy/PC mixtures after heating suggests a crosslinked network formation. The majority of the crosslinks possess primarily $\phi-\mathrm{O}-(\mathrm{CO})-\mathrm{O}-\mathrm{C}$ linkages and to a less extent $\mathrm{C}-\mathrm{O}-$
(CO)-O-C linked groups, indicating more exchange reactions (transreaction and/or alcoholysis) between the functional groups in the epoxy hydroxyl and PC carbonate groups.

Changes of morphology of the crosslinked network structure during reactions were examined. The ultimate morphology of the extensively reacted epoxy/PC samples revealed a fully crosslinked network, totally unaffected by the solvent. However, intermediate morphology is quite complex, suggesting that crosslinking may not be uniform before the final stage of network formation. To identify the intermediate structure before final crosslinking, the epoxy/PC samples heated for intermediate time were separated into solute and leached solid samples. IR analyses for the extracted solutes and leached solid portions helped to determine the relative distribution of low- $M_{w}$ fragmented chains or unreacted epoxy molecules in the cross-linked network.

Acknowledgment. The authors are grateful for the instrument support provided by Regional Analytical Instrument Center (Tainan, Taiwan) administered by National Science Council (NSC). Research grant \#NSC 85-2216-E006-006 was kindly provided by NSC.

\section{REFERENCES}

1. C. C. Su, J.-F. Kuo, and E. M. Woo, J. Polym. Sci., Polym. Phys., 33, 2235 (1995). 
2. C. C. Su and E. M. Woo, Macromolecules, 28, 6779 (1995).

3. E. M. Woo and M. N. Wu, Polymer, 37, 2485 (1996).

4. M. N. Wu and E. M. Woo, J. Polym. Sci., Polym. Phys., 34, 789 (1996).

5. M. Abbate, E. Martuscelli, P. Musto, G. Ragosta, and G. Scarinzi, J. Polym. Sci., Polym. Phys., 32, 395 (1994).

6. E. M. Woo and S. N. Yau, J. Polym. Sci., Polym. Chem. Ed., 35, 97 (1997).

7. T. Ohsako, K. Nagura, and I. Nozue, Polymer, 34, 5080 (1993).

8. M. C. Chen, D. J. Hourston, and W. B. Sun, Eur. Polym. J., 28 1471 (1992).

9. C. B. Bucknall, I. K. Partridge, L. Jayle, I. Nozue, A. Fernyhough, and I. N. Hay, Polym. Prepr. Am. Chem. Soc. Div. Polym. Chem., 33(1), 378 (1992).

10. T.-M. Don and J. P. Bell, J. Polym. Sci., Polym. Chem., 34, 2103 (1996).

11. M. S. Li, C. C. M. Ma, J. L. Chen, M. L. Lin, and F. C. Chang, Macromolecules, 29, 499 (1996).

12. C. C. Su, E. M. Woo, C.-Y. Chen, and R. R. Wu, Polymer, accepted to appear (1997).

13. C. C. Price and D. D. Carmelite, J. Am. Chem. Soc., 88, 4039 (1966).

14. A. J. Attias, B. Bloch, and F. Laupretre, J. Polym. Sci., Polym. Chem., 28, 3445 (1990). 